\title{
Awareness of prostate cancer:A research study on Syrian private university students, Syria
}

\begin{abstract}
Prostate cancer is one of the most commonly occurring cancers in men, in 2018 there were 1.3 million new cases, according to a study conducted by the American Institute for Cancer Research, resulting in a significant rate of deaths. Needless to mention that there is a lack of efforts to make this disease noticeable by public as being made in carcinoma of Breast in women. Our study aims to determine the knowledge level of student at the Syrian Private University concerning as well as raising awareness about prostate cancer. A cross-sectional study was done at the Syrian Private University in Damascus, Syria, between December 2020 until January 2021. The sample included students of all years from different faculties in the Syrian Private University. The data was collected by a questionnaire to measure the awareness of prostate cancer. The total number of participants was 446, from all faculties including males and females. The number of students who have heard about Prostate Cancer was $73.1 \%$, and the percentage, of those who heard about the PSA Test was $52 \%$. As for students of medical faculties from various years the percentage was $62.3 \%$ compared to non-medical faculties, where the percentage was only $19.5 \%$, therefore it was clear that the practical side was weak among Non-medical faculties. This study showed a lack of knowledge about the risk factors of prostate cancer and its early detection methods, especially in non-medical faculties, It appeared that the most important reason is the lack of health awareness programs in Syria, accordingly it is very important in our society to encourage producing a campaign for the benefits of making the Syrians are aware of the risk of cancer of prostate. It's well known within the medical profession that the first step against prostate cancer and its mortality is early detection, which requires the support of health awareness campaigns to explain the risk of the disease and related symptoms, and the proper management.
\end{abstract}

To achieve our target, all public activities including the media, social network, and in addition to encourage the males approaching the age of at fifty years to participate in an investigating program aiming for early detection of prostatic malignancy before local or distant metastasis, bearing in mind that PSA test may represent the prim attempt to combat this killing disease, however it's very important to raise the flag and stress that this publicity will not produce the complete protection of our males Syrians as it is well known that raised PSA means that cancer of prostate is already at least disseminated out the prostatic capsule, obviously the next step in our recommendation is the performance of precautionary magnetic resonance imaging (MRI) for the prostate as there may be a sign detected of prostatic sub capsular localized malignant lesion and this will pave the way towards performing ultrasound guided needle biopsy or fine needle aspiration Consequently, we are also looking forward to dedicate a month every year to enhance knowledge of prostatic malignancy, increase screening tests, and support free examinations sponsored by the health authority. By achieving this target we may be able to declare that we have a proper awareness program to combat prostate cancer in Syria.

Keywords: prostate cancer, awareness, students, knowledge, Syria
Volume I2 Issue 2 - 202I

\author{
Sara Restum, ${ }^{2}$ Mazen Alloush, ${ }^{2}$ Muhammad \\ Assem Kubtan' \\ 'Head of Department of Surgery, Faculty of Medicine, Syrian \\ Private University, Syria \\ ${ }^{2}$ Department of Surgery, Faculty of Medicine, Syrian Private \\ University, Syria
}

Correspondence: Muhammad Assem Kubtan, Head of Dep't of Surgery, Faculty of Medicine, Syrian Private University, Damascus, Syria, Tel 0096394427 I2 I5, Email makubtan@gmail.com

Received: March 02, 2021 | Published: March 29, 2021

\section{Introduction}

Prostate cancer is the second most common type of cancer after lung cancer among men and the fourth most common cancer in general, with the incidence of about 1.3 million men in 2018 in 20 countries around the world. ${ }^{1}$ A study in the UK in 2017 showed that prostate cancer is the second most common cause of death in men. There are around 12,000 deaths in the UK every year caused by prostate cancer, which is about 32 deaths per day. This means that prostate cancer accounts for approximately $14 \%$ of all cancer deaths in men in the $\mathrm{UK}^{2}$
Consequently, prostate cancer is one of the main cancers which affect men in both developing and developed countries. At least in the developing countries despite of periodic or incidental examination there is no efforts been implemented to draw attention of the public and health awareness campaigns for early detection of prostate cancer, apparently this disease commonly is not diagnosed in its early stages. Therefore, as there is a necessity for early diagnosis to reduce the mortality caused by prostate cancer, and in comparison with the efforts locally and internationally being carried out through all types of media to expand the knowledge of people concerning Breast Cancer 
in Females there is a desire lack of attempts to bring the facts and risks of Prostatic Cancer to the attention of citizens. Accordingly in our opinion there should be an efforts instituted to bring this dilemma to the attention of the people and to make the males aware of this risk, this ideas brought us to commence a researchable study starting with a universities students of various colleges, to find out the range of their knowledge concerning prostatic cancer as they represent a samples of the population that they did not approach yet the age of the appearance of prostatic symptoms. It appeared from the literature that even in the developed countries also there are a lack in planning to limit the morbidity and mortality resulted from this disease .discover this disease as early as possible since the most usable investigation is the Prostate Specific Antigen which usually raised in association with development of Prostatic Cancer, apparently with the exclusion of limited number of cases associated with raised PSA of benign prostatic diseases we can't deny the scientific facts prove that elevated PSA means that prostatic cancer is already has disseminated locally through the prostatic capsule and even may be distally.

Hence, it is important to raise the attention of the public about this disease hoping to reduce the mortality and morbidity of this disease, this target would not be achieved unless the media social authorities and health authority backed with medical presentations to draw the attention of the general public and encourage males departing their fourth decades to carry out a regular clinical and laboratory examinations for early diagnosis of prostate cancer. Obviously this would not be enough and can't be achieved unless it is associated with MRI study to detect the early appearance of prostate cancer within the prostatic sub capsular tissue and before dissemination locally and distally have taken place, when prostatic needle biopsy or fine needle aspiration cytology FNAC becoming indicated (Figure 1). ${ }^{3}$

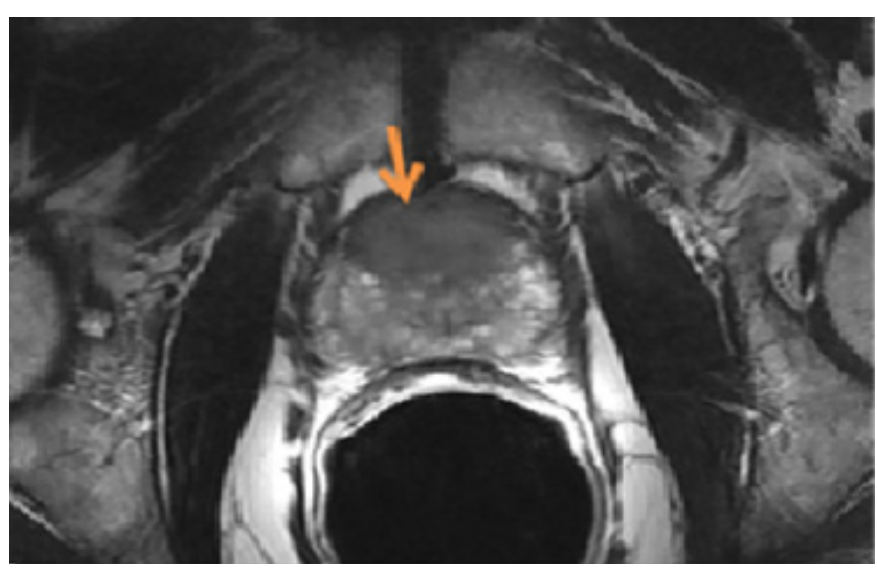

Figure I Localised Ca Prostate within prostatic capsule not yet desiminted.

\section{Methods}

A cross-sectional study was done at the Syrian Private University in Damascus between December 2020 and January 2021. The study included 446 students both male and female of all years from different colleges included Medicine, Informatics engineering, Dentistry, Petrol engineering, Pharmacy and Business administration. Simple randomization method was used for the distribution. Data collection was done by an online survey. The questionnaire consisted of forty-seven 47 questions divided into four sections (general information, symptoms, risk factors and methods of early detection of prostate cancer), in addition to socio-demographic and descriptive characteristics (age, educational level, marital status, having a relative doctor, having an affected relative and habits).

\section{Results: analysis}

This Survey was divided into four enquiry sections; each one shows a different aspect of prostate cancer:

\section{Prostate cancer knowledge}

We found that $67.9 \%$ of the Faculty of medicine students had correct answers, which is the highest percentage, while the percentages of the Faculties of Dentistry and Pharmacy were close (64.1\%) (64.5\%), respectively, and the Faculties of Informatics and Petrol Engineering had a low level of awareness. The percentage of the College of Business Administration was (56.8\%), which is the highest rate among non-medical colleges. Accordingly we can deduct from the above that medical students are the most aware of the disease, and the grand total of students 'awareness in general about the first section was $60.6 \%$.

\section{Prostate cancer symptoms}

We found that the percentages of the Faculties of Medicine and Dentistry are close $(73.1 \%)$ and $(74.1 \%)$, respectively. As for the Faculty of Business Administration, the level of awareness about disease symptoms was high and noticeable, reaching (71.6\%) despite it being a non-medical college, as for the Faculty of Pharmacy, its percentage reached (64.7\%), the Faculty of Informatics Engineering $(60.6 \%)$, and the Faculty of Petrol Engineering (45.9\%), which is a low percentage. We concluded from the above that the awareness level of disease symptoms for both medicine and dentistry are close, but the Faculty of Dentistry is the highest and the Faculty of Business Administration has a high awareness, and the overall student awareness of the second section reached $68.2 \%$.

\section{Prostate cancer risk factors}

We found that the percentages of the faculties of medicine and dentistry are close $(64.8 \%)$ and $(65.5 \%)$, respectively, followed by the Faculty of Pharmacy $(60.3 \%)$ and the Faculty of Business Administration $(59.8 \%)$. We concluded from the above that the awareness level of risk factors for both medicine and dentistry are close, but the College of Dentistry is the highest, and the grand total of students 'awareness in general on the third section is $61.6 \%$ (Figure 2).

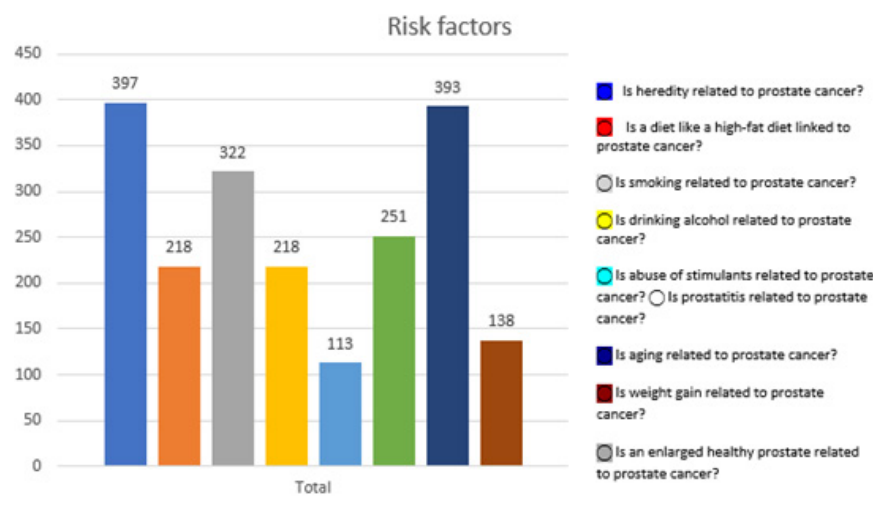

Figure 2 Risk factors.

\section{Prostate cancer early detection methods}

We found that the percentage of the Faculty of Medicine is the highest, reaching $(76.2 \%)$, followed by the Faculty of Dentistry $(66.3 \%)$. As for both information technology and engineering, the awareness percentage was significantly low. Medical students were 
the most aware of the methods of detecting disease, and the grand total of students 'awareness in general about the first section was $61.0 \%$ (Figure 3).

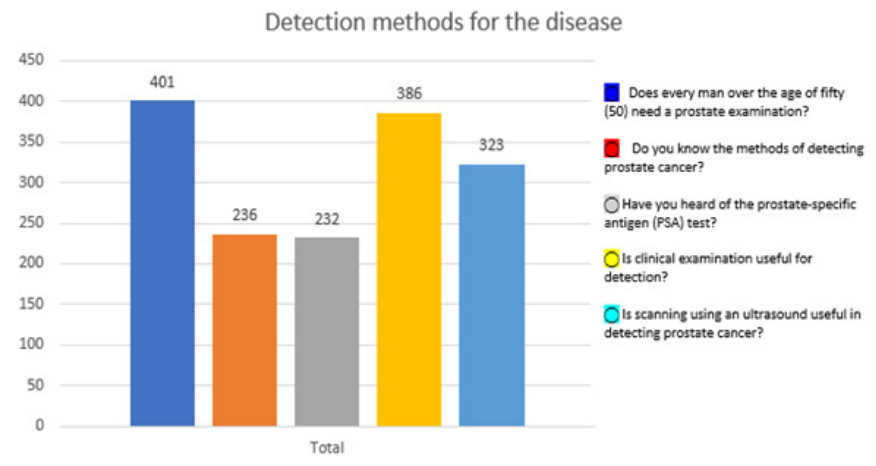

Figure 3 Detection methods for the disease.

\section{Discussion}

a. According to this study, $73.1 \%$ of college students from various faculties have heard about prostate cancer.

b. In this study, $52.9 \%$ of students have confirmed in this questionnaire that they know about early detection methods of prostate cancer and $52 \%$ have confirmed that they have heard about the PSA test which is almost equal percentage. These percentages indicate correct answers to the questions about prostate cancer reflect the level of knowledge about symptoms, risk factors and methods of early detection of this disease in the younger generation.

c. We also noted that the outcome of student's awareness about the symptoms of prostate cancer was $68.2 \%$, but as for the question "no symptoms" the percentage of students who answered the answer "yes" was only $26.7 \%$. This indicates that $73.3 \%$ of students do not know that prostate cancer could be asymptomatic initially.

d. The outcome of student's awareness about the risk factors of prostate cancer was $61.6 \%$, but when asked "is weight gain related to prostate cancer?" the percentage of students who answered "yes" was $30.9 \%$. This indicates that $69.1 \%$ of students do not know that being overweight is linked to prostate cancer. $^{4-12}$

\section{Conclusion}

According to the above, globally there is a lack of early diagnosis of prostate cancer despite performing PSA as it is impossible to rule out the presence of prostatic cancer in the early stages. The use of (MRI) should significantly alter the prognosis for prostate cancer. The MRI images are highly sensitive to this aggressive disease before even before noticing any raise in PSA meanwhile it is very important to mention that negative PSA raised value can't be considered as a full assurance to the safety of prostate in the meantime normal MRI will avert the necessity for multiple Needle biopsy or FNAC. Therefore,
MRI is recommended as a real test for men whom they are departing their fourth decade, obviously MRI shouldn't be recommended only once and should be recommended on regular basis especially in the presence of history of heredity, this should encourage health professionals to work on further research project to find the proper timing for repeating this expensive test looking for prostate cancer as early as possible. It is still that early diagnosis of prostatic cancer represent a real challenge to Urologists since MRI is an expensive investigation especially in developing societies, this need for the health professionals to work on developing a proper and uncostly investigations may be trans rectal ultrasound study.

\section{Acknowledgments}

We are in depth to Dean of Faculty of Medicine SPU, Prof. N Al Daher for his ethical support and encouragements.

\section{Competing interests}

The authors declare no competing interests.

\section{References}

1. Bray F, Ferlay J, Soerjomataram I, et al. Global Cancer Statistics 2018: GLOBOCAN estimates of incidence and mortality worldwide for 36 cancers in 185 countries. CA Cancer J Clin. 2018;68(6):394-424.

2. Rawla P. Epidemiology of Prostate Cancer. World J Oncol. 2019;10(2):6389.

3. Fenton JJ, Weyrich MS, Durbin S, et al. Prostate-Specific Antigen-Based Screening for Prostate Cancer: A Systematic Evidence Review for the U.S. Preventive Services Task Force. JAMA. 2018;319(18):1914-1931.

4. Kelly SP, Rosenberg PS, Anderson WF, et al. Trends in the Incidence of Fatal Prostate Cancer in the United States by Race. Eur Urol. 2017;71(2):195-201.

5. Carioli G, Bertuccio P, Boffetta P, et al. European cancer mortality predictions for the year 2020 with a focus on prostate cancer. Ann Oncol. 2020;31(5):650-658.

6. Reda I, Khalil A, Elmogy M, et al. Deep learning role in early diagnosis of prostate cancer. Technol Cancer Res Treat. 2018;17:1533034618775530.

7. Dong DX, Ji ZG. Current progress and controversies in prostate cancer management. Chin Med J (Engl). 2017;130(24):2991-2995.

8. Carter HB, Albertsen PC, Barry MJ, et al. Early detection of prostate cancer: AUA Guideline. J Urol. 2013;190(2):419-426.

9. Rendon RA, Mason RJ, Marzouk K, et al. Canadian Urological Association recommendations on prostate cancer screening and early diagnosis. Can Urol Assoc J. 2017;11(10):298-309.

10. Schröder FH, van der Cruijsen-Koeter I, de Koning HJ, et al. Prostate cancer detection at low prostate specific antigen. $J$ Urol. 2000;163(3):806812 .

11. Carroll PR, Parsons JK, Andriole G, et al. Prostate cancer early detection, version 1.2014: Featured updates to the NCCN Guidelines. J Natl Compr Canc Netw. 2014;12(9):1211-1219.

12. Friedrich MJ. Debate continues on use of PSA testing for early detection of prostate cancer. JAMA. 2011;305(22):2273-2275. 